\title{
DENSIDADE RADICULAR DO MILHO CONSIDERANDO OS ATRIBUTOS DE UM SOLO COM HORIZONTE B TEXTURAL ${ }^{(1)}$
}

\author{
J. A. ALBUQUERQUE ${ }^{(2)} \&$ D. J . REINERT ${ }^{(3)}$
}

\begin{abstract}
RESUMO
A absorção de água e nutrientes pelas plantas depende de vários fatores, principalmente do volume de solo explorado pelas raízes. Determi nados fatores e, ou, processos ocorridos no solo podem limitar o crescimento das raízes. Este estudo objetivou: (a) quanti ficar as relações entre densidade radicular da cultura do milho e alguns atributos de um Argissolo Vermelho distrófico arênico e identificar quais desses atributos restringem o crescimento de raízes no horizonte $B_{t}$ e a produtividade do milho; (b) monitorar a variação temporal de água no solo para avaliar a extração de água do horizonte $B_{t}$. $O$ estudo foi realizado com mi lho no sistema plantio direto, no ano agrícola de 93/94, em um Argissolo Vermelho distrófico arênico, localizado na área experimental do Departamento de Solos da Universidade Federal de Santa Maria. Foram analisados a microporosidade, macroporosidade, porosidade total, densidade do solo, espaço aéreo, textura, concreções, resistência à penetração, cálcio + magnésio, saturação por alumínio, densidade radicular e produtividade do milho. Observando os perfis culturais e a densidade radicular, percebeu-se que o horizonte $B_{t}$ restringiu o crescimento radicular, principalmente nos perfis com horizonte $A$ raso, quando comparados aos perfis com horizonte $A$ profundo. A densidade do solo e a resistência à penetração não restringiram o cresci mento radicular nas condições estudadas; já a presença de concreções e a elevada saturação por alumínio trocável foram as variáveis que mais restringiram o crescimento radicular. Não foi observada redução da umidade volumétrica do horizonte $B_{t}$ durante o ciclo de crescimento do milho, mesmo em prolongado período de déficit hídrico, indicando que a água presente neste horizonte não foi absorvida pela cultura, considerando a baixa densidade radicular neste horizonte. A produtividade de grãos de milho foi reduzida em $23 \%$ nos perfis com horizonte A raso, comparado aos perfis com horizonte A profundo, provavelmente por causa da restrição ao crescimento radicular.
\end{abstract}

Termos de indexação: crescimento de raízes; absorção de água; produtividade do milho.

(1) Recebido para publicação em maio de 2000 e aprovado em fevereiro de 2001.

(2) Professor do Departamento de Solos, Universidade do Estado de Santa Catarina - UDESC. Campus III, Caixa Postal 281, CEP 88520-000 Lages (SC). E-mail: a2ja@cav.udesc.br

(3) Professor do Departamento de Solos, Universidade Federal de Santa Maria - UFSM. CEP 97119-900 Camobi, Santa Maria (RS). Pesquisador do CNPq. 


\title{
SUMMARY: RESTRICTION TO ROOT GROWTH IN THE B TEXTURAL HORIZON
}

\begin{abstract}
Plant water and nutrient uptake depends on several factors, mainly on the soil depth explored by theroots. Somesoil factors and processes can li mit root growth. The objectives of this study were: (a) to quantify the relationships among corn root density with several soil properties and to identify which of theseattributes restrict root growth in the $B_{t}$ horizon and corn yidd; (b) to measurethetemporal variation of thesoil water content to verify if plants extract water from the $B_{t}$ horizon. The study was carried out with corn under no tillage during the 93/94 growing season at the Federal University of Santa Maria on a Typic Hapludalf soil. Porosity, bulk density, aerial space, texture, gravel, resistanceto penetration, cal cium + magnesium, saturation with aluminum, root density and corn yield wereanalyzed. Through the observation of the cultural profiles and root density, it was noticed that the horizon $B_{t}$ restricted root growth, mainly in the profiles with shallow $A$ horizon when compared to deep A horizon. The soil bulk density and resistance to penetration did not restrict root growth. Conversely, thegraved presenceand thehigh saturation with exchangeable al uminum were the variables that strongly restrict root growth. Reduction of the moisture content of the $B_{t}$ horizon was not observed during thecorn growth, even under dry conditions, indicating that low root density probably prevented the plants to take up water in the $B_{t}$ horizon. Corn yield was $23 \%$ lower in the profiles with shallow A horizon than in profiles with deep A horizon. This yield decrease was probably a function of the restriction to the root growth.
\end{abstract}

Index terms: soil properties, water uptake, corn yield.

\section{NTRODUÇÃO}

A densidade e a distribuição de raízes são indicativos da qualidade do sol o para o crescimento das plantas e dependem de alguns atributos determinantes dos processos de absorção de água e nutrientes (Oussible et al., 1992; Eghball \& Maranville, 1993). Para entender as variações na produtividade das culturas, no espaço e no tempo, são necessários estudos queaval iem as propriedades do sol o e suas relações com o crescimento radicular (Veen \& Boone, 1990; Pagès \& Pellerin, 1994).

Em um Argissolo Vermel ho distrófico arênico da área experimental do Departamento de Solos da UFSM, observou-se que o crescimento e a produção de matéria seca e de grãos da cultura do milho estavam sendo restringi dos, pois as raízes da cultura não penetravam no horizonte $B_{t}$. Estudos anteriores indicaram que esta restrição estava relacionada com a menor espessura do horizonte $A$, porém os processos ou fatores que causavam restrições à cultura, embora não conhecidos (Albuquerque et al., 1996; Fiorin et al., 1997), reduziam a produtividade das culturas (Langdaleet al., 1979; Swan et al., 1987; Albuquerque et al., 1994).

Alguns atributos dosol o quealteram ocrescimento radicular são: temperatura, umidade, energia de retenção da água, textura, densidade do solo, distribuição detamanho de por os, resistência do solo à penetração, acidez e fertilidade do solo (Logsdon et al., 1987; Veen \& Boone, 1990).
A menor produção verificada em Podzólicos (Argissolos) com horizonte A pouco "profundo" é devida às forças de capilaridade e adsorção, visto que a água existente no horizonte $B$ textural não ascende para o horizonte $A$, mais arenoso, onde estão concentradas as raízes (Fiorin et al., 1997). A restrição ao crescimento radicular reduz mais a produtividade das culturas em anos em que ocorre déficit hídrico (Langdale et al., 1979; Swan et al., 1987; Fiorin et al., 1997), pois, quando camadas adensadas ocorrem próximas à superfície do solo, verifica-se concentração de raízes acima dessas camadas (Oussible et al., 1992; Rosolem et al., 1994).

Nos casos em que ocorre restri ção ao crescimento radicular, a erosão hídrica reduz ainda mais o volume de sol o expl orado pelas raízes (Nizeyimana \& Olson, 1988) e, conseqüentemente, o teor de água e nutrientes disponíveis, principal mecanismo pelo qual a erosão diminui a produtividade do solo (Willians et al., 1981).

Um dos principais atributos físicos que reduz a produtividade das culturas é a densidade do solo e sua relação com a resistência à penetração. $\mathrm{O}$ aumento da densidade do sol o geral mente acarreta maior resistência à penetração (Vyn \& Raimbault, 1993; Rosolem et al., 1994), propriedade esta também influenciada pela umidade e textura. Rosolem et al . (1994) observaram que o aumento da densidade do sol o de 1,03 para 1,72 $\mathrm{g} \mathrm{cm}^{-3}$ aumentou a resistência à penetração de 0,05 para 2,0 M Pa, causando total impedimento ao crescimento de raízes de milho. 
Segundo Gerard et al. (1982), com o aumento do teor de argila, a resistência crítica que cessa a el ongação radicular torna-se menor. Todavia, o efeito da diminuição da resistência crítica nos solos mais argil osos pode ser amenizado com a maior retenção deágua nesses sol os, também observada em subsolos argilosos.

Logsdon et al. (1987) determinaram que a redução do potencial matricial de água no solo de -0,2 para -1,1 M Pa diminuiu significativamente o crescimento radicular de plantas de milho, avaliado seis dias após a emergência. Logsdon et al. (1987) e Veen \& Boone (1990) verificaram que o aumento da resistência mecânica reduziu o comprimento radicular, porém aumentou o raio das raízes. Afirmaram que este aumento do raio pode ser devido ao menor crescimento de raízes laterais que mostram raio menor do que as raízes principais. $O$ aumento no raio das raízes torna-se mais problemático, pois, em geral, a compactação também diminui o tamanho dos poros. Conforme Hill \& Cruse (1985), quando a densidade do sol o aumenta, verifica-se uma redução do volume de poros maiores, bem como um aumento do volume de poros menores que $15 \mu \mathrm{m}$ de raio.

A hipótese deste estudo é de quea água existente no horizonte $B$ textural não está disponível para as culturas, já que as raízes dificilmente penetram nesse horizonte e o movimento ascendente de água para o horizonte A pode ser limitado.

Os objetivos do trabal ho foram: (a) quantificar as relações entre densidade radicular da cultura do milho e al guns atributos de um Argissolo Vermel ho distrófico arênico e identificar quais desses atributos restringem o crescimento de raízes no horizonte $B_{t}$ ea produtividade do milho; (b) monitorar a variação temporal de água no solo para avaliar se as plantas extraem água do horizonte $\mathrm{B}_{\mathrm{t}}$.

\section{MATERIAL E MÉTODOS}

O experimento foi realizado na área do Departamento de Solos, Centro de Ciências Rurais, noCampus da UniversidadeFederal de Santa Maria, Santa Maria (RS), região fisiográfica da Depressão Central do Rio Grande do Sul. A latitude do local é de $29^{\circ} 41^{\prime}$ S, a longitude de 53०48' W e a altitude de 95 m. O clima do local, segundo a classificação de Köeppen, é $\mathrm{Cfa}$, temperado moderado chuvoso, com a temperatura do mês mais frio entre -3 e $18^{\circ} \mathrm{C}$ e a temperatura do mês mais quente superior a $22^{\circ} \mathrm{C}$. A preci pitação média anual varia de 1.322 a $1.769 \mathrm{~mm}$ (Moreno, 1961).

O solo foi classificado como Argissolo Vermel ho distrófico arênico (EMBRAPA, 1999), anteriormente classificado como Podzólico Vermel ho-Amarelo Tb distrófico (Brasil, 1973); apresenta declividade de $0,06 \mathrm{~m} \mathrm{~m}^{-1}$, textura superficial franco-arenosa e subsuperficial franco-argilosa. A descrição geral e morfológica de um perfil localizado na área experimental foi realizada por Fiorin (1993).

A área do experimento, de 2 ha, foi subdividida em cinco faixas através de terraços de base média e cultivada nosistema plantio direto a partir de 1989. Em 1988, antes da instalação do sistema plantio direto, a acidez do sol o foi corrigida para pH próximo a 6,0 .

O presente estudo foi iniciado em maio de 1993, com a semeadura de aveia consorciada com ervilhaca em todas as cinco faixas entre terraços. Na quarta faixa, na fase de floração, foi aplicado dessecante foliar para interromper o crescimento da aveia. O mil ho foi semeado em 8 de outubro de 1993 (cultivar CARGIL 511 A), com um espaçamento de 1 m entre linhas e seis sementes por metro linear. A adubação do milho constou de $250 \mathrm{~kg} \mathrm{ha}^{-1}$ da formulação 520-20, incorporado ao solo no momento da semeadura. No estádio V10 da cultura, foram distribuídos $100 \mathrm{~kg} \mathrm{ha}^{-1}$ de uréia na linha de semeadura. O controle de plantas daninhas foi efetuado com o herbicida TRIAMEX na dose de 5 L ha-1, aplicado em 27 de outubro de 1993.

Com base no estudo de Al buquerque et al . (1992), foram sel ecionados quatro pontos deobservação: dois com horizonte A "profundo" (profundo 1 e profundo 2), com a transição entre o horizonte $A$ ou $E$ e o $B$ textural aos $0,80 \mathrm{~m}$, e dois com horizonte $A$ "raso" (raso 1 e raso 2), com a transição entre o horizonte $A$ ou $E$ eo $B$ textural aos $0,40 \mathrm{~m}$. Os perfis foram abertos eas col etas de sol o e raízes realizadas de 05 a 12 de janeiro de 1994, no estádio do pendoamento da cultura do milho, período no qual, segundo Mengel \& Barber (1974), o sistema radicular do milho al cança a máxima extensão.

Nos pontos "profundos", os perfis tiveram 1,2 m de profundidadee, nos pontos "rasos", 0,7 m. O perfil analisado foi perpendicular à linha de semeadura de milho, com a parede vertical do perfil distante de $3 \mathrm{~cm}$ da planta de milho. Foi utilizada uma faca para retirar uma camada de solo de $1,5 \mathrm{~cm}$ do perfil, expondo cui dadosamenteas raízes. Após a exposição das raízes, um quadro com 1,0 m de lado, subdividido com fio de náilon formando uma mal ha de $5 \times 5 \mathrm{~cm}$ foi utilizado para desenhar a distribuição radicular no perfil.

Nos pontos com horizonte A "profundo", foram col etadas amostras nas profundidades de $0,20,0,45$, 0,70 e 0,90 m e, nos pontos com horizonte A "raso", foram col etadas amostras nas profundidades de 0,20, 0,45 e 0,60 m, demarcadas conformea profundidade e espessura dos horizontes do solo. Em cada profundidade, foram demarcados dois pontos para col eta, um à esquerda e outro à direita da linha de plantio (planta). Portanto, para cada perfil "profundo", foram amostrados oito pontos e, para cada perfil "raso", seis pontos, totalizando 28 amostras. 
Para as determinações químicas, textura e densidade de partículas, foi coletada em cada ponto uma amostra de aproximadamente $1,5 \mathrm{~kg}$ de solo com estrutura deformada. Para avaliar a macroporosidade, mi croporosidade, porosi dadetotal e densidade do solo, foram col etadas em cada ponto três amostras indeformadas em torrões e, para determinar a densidade radicular e a percentagem de concr eções no solo, foram col etadas em cada ponto amostras com $15 \mathrm{~cm}$ de largura, 15 de comprimento e 10 de altura, totalizando um volume de $2.250 \mathrm{~cm}^{3}$.

O alumínio e o cálcio + magnésio foram obtidos segundo EMBRAPA (1979). A granulometria foi determinada por meio do método do densímetro. A densidade de partículas foi obtida pelo método do balão vol umétrico e a densi dade do solo pel o método do torrão parafinado (EMBRAPA, 1979). A porosidade total foi calculada, utilizando a seguinte fórmula:

$$
\mathrm{PT}=1-\left(\frac{\mathrm{Ds}}{\mathrm{Dp}}\right) * 100
$$

em que PT é a porosidade total $\left(\mathrm{cm}^{3} \mathrm{~cm}^{-3}\right)$, Ds é a densidade do solo $\left(\mathrm{g} \mathrm{cm}^{-3}\right)$ e $\mathrm{Dp}$ a densidade de partículas $\left(\mathrm{g} \mathrm{cm}^{-3}\right)$. A microporosidade foi obtida por meio da determinação da umidade dos torrões, submetidos a uma tensão de 0,006 MPa. A macroporosidade foi calculada pela diferença entre a porosidade total ea micropor osidade (EMBRAPA, 1979).

A umidade volumétrica foi monitorada da semeadura até a maturação fisiológica do milho, nas profundidades de 0,10, 0,25, 0,46, 0,70 e 0,93 m. Para isso, for am instalados tubos de acesso para a sonda de nêutrons, dois na área com horizonte A "raso" e dois na área com A "profundo". O número de contagens da sonda de nêutrons foi convertido em umidade volumétrica mediante a calibração realizada na área deste estudo (Fiorin, 1993). O espaço aéreo, a diferença entre a porosidade total e a umidade volumétrica foram calculados para a profundidadede $0,45 \mathrm{~m}$, profundidademáxima em que foram observadas raízes nos perfis com horizonte $A$ "raso".

A resistência à penetração foi determinada com um penetrômetro de bolso, marca Soiltest I nc. modelo $\mathrm{CL}-700$, com graduação de $0-5 \mathrm{~kg} \mathrm{~cm}^{-2}$. Determinou-se a máxima força necessária para que a extremidade cilíndrica com 4,8 mm de diâmetro penetrasse $5 \mathrm{~mm}$ dentro do solo. Em cada ponto de amostragem, foram realizadas dez leituras para comporem um valor médio de resistência à penetração.

As raízes e as concreções foram separadas da massa de solo, utilizando um jogo de três peneiras sobrepostas com diâmetros de 2,0, 1,0 e 0,5 mm. As concreções, após serem separadas do solo, foram lavadas em solução de hidróxido de sódio, para retirar o solo aderido, e secas em estufa a $105^{\circ} \mathrm{C}$. A massa de concreções foi expressa em relação ao peso total da amostra.

O solo com raízes foi col ocado na peneira superior e, com jatos de água, foram separadas, cuidadosamente, as raízes do solo. As raízes foram colocadas em saco plástico que continha uma parte deálcool e duas partes de água para a conservação até à contagem. Para estimar o comprimento radicular, utilizou-se o método da interseção de Newman modificado por Tennant (1975) por meio da seguinte fórmula:

$$
\mathrm{R}=\mathrm{N} * \frac{11}{14} * \mathrm{UQ}
$$

em que UQ éa unidade do quadriculado $(2 \mathrm{~cm})$ e $\mathrm{N}$ é o número de interseções, sendo $\mathrm{R}=\mathrm{N} * 1,5714$. $\mathrm{O}$ resultado expresso em unidade de comprimento radicular $(\mathrm{cm})$ foi dividido pelo volume da amostra de solo $\left(2.250 \mathrm{~cm}^{3}\right)$, resultando em comprimento de raízes por volume de solo $\left(\mathrm{cm} \mathrm{cm}^{-3}\right)$.

A col heita do milho foi realizada em 15 de março de 1994, em áreas próximas a cada perfil, em três fileiras com 10 m de comprimento, totalizando uma área de $30 \mathrm{~m}^{2}$.

Os dados foram analisados por meio de regressão linear simples e múltipla pelo método "stepwise" (SAS, 1990).

\section{RESULTADOS E DISCUSSÃO}

A densidade radicular do milho foi reduzida com a profundidade, de $2,51 \mathrm{~cm} \mathrm{~cm}^{-3}$ na profundidade de $0,20 \mathrm{~m}$ para $0,21 \mathrm{~cm} \mathrm{~cm}^{-3}$ na profundidade de $0,95 \mathrm{~m}$ (Quadro 1), val ores semel hantes aos observados em outros estudos. Silva et al. (2000) em um Podzólico Vermel ho-Amarelo, considerando a média dos sistemas de preparo convencional e plantio direto, observaram uma densidade radicular de $3,0 \mathrm{~cm} \mathrm{~cm}^{-3}$

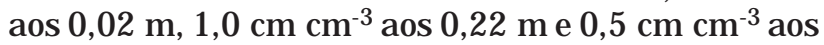
0,37 m de profundidade. Em um Podzólico Vermel hoEscuronoRio Grande do Sul, Mellolvo \& Mielniczuk (1999), na camada de 0,25 a 0,35 m, observaram uma densidade radicular de $1,7 \mathrm{~cm} \mathrm{~cm}^{-3}$, no preparo convencional, e de 1,8 $\mathrm{cm} \mathrm{cm}^{-3}$, no plantio direto.

Foi observada restrição ao crescimento das raízes nos dois perfis "rasos", onde o horizonte B textural $\left(B_{t}\right)$, ou uma camada concrescionária, foi detectado aos 0,4 $\mathrm{m}$ da superfície (Figura 1 ). Nos dois perfis com horizonte $A$ "profundo", o horizonte $B_{t}$ iniciou aos $0,8 \mathrm{~m}$ de profundidade. Nestes perfis, apesar de as raízes terem penetrado pouco no horizonte $B_{t}$ (Figura 2), o volume de sol o explorado pelas raízes e, portanto, o suprimento de nutrientes eágua para as plantas foram superiores aos dos perfis com horizonte A "raso". 
Quadro 1. Profundidade de coleta, horizonte, densidade radicular (DR), cálcio mais magnésio, saturação por alumínio (m), microporosidade (Mic), macroporosidade (Mac), porosidade total (PT), densidade do solo (Ds), concreções, argila, silte, areia e resistência à penetração (RP), nos perfis profundos e rasos do Argissolo Vermelho distrófico arênico. Cada valor representa a média das determinações realizadas à esquerda e à direita da planta

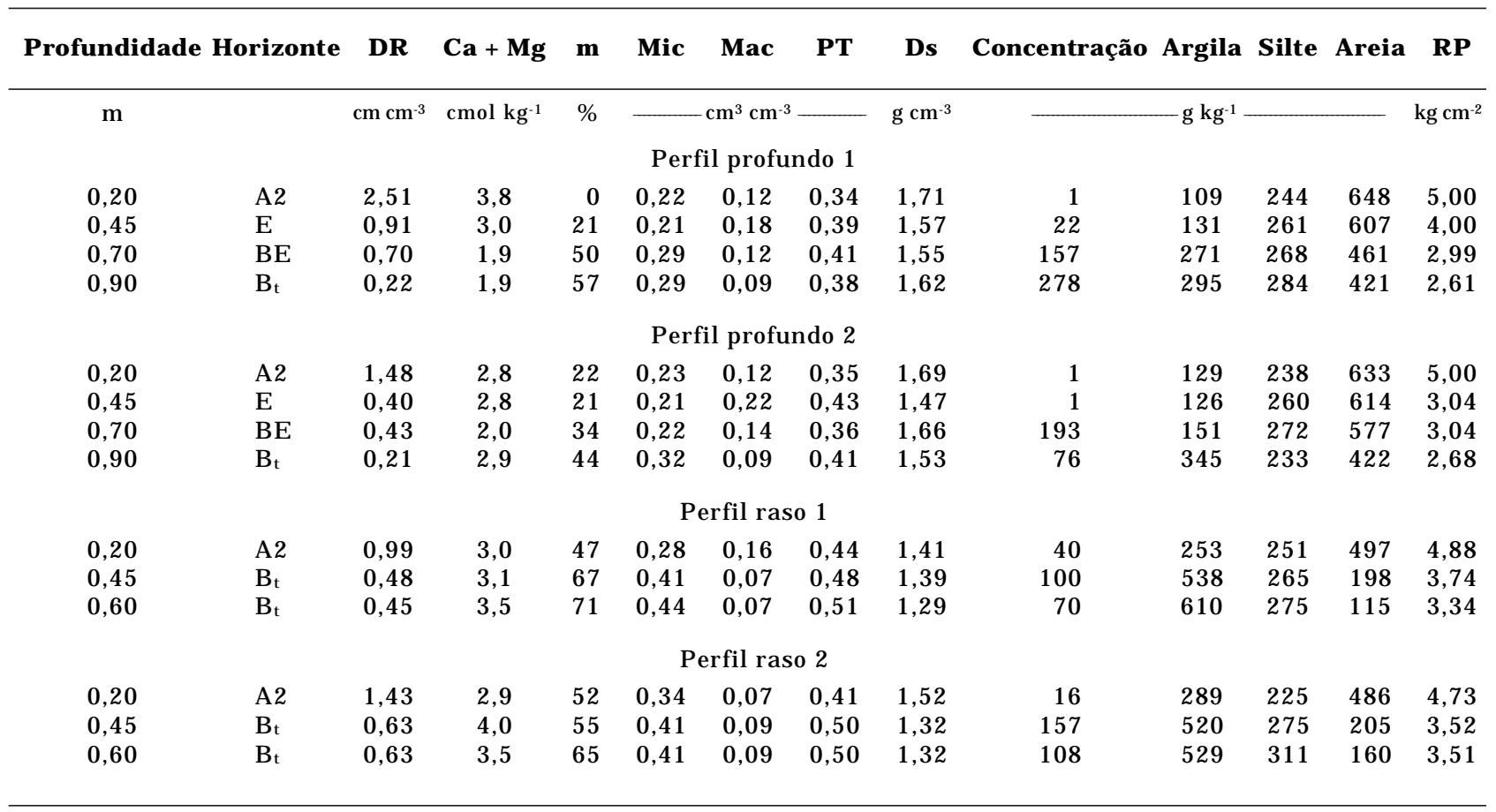

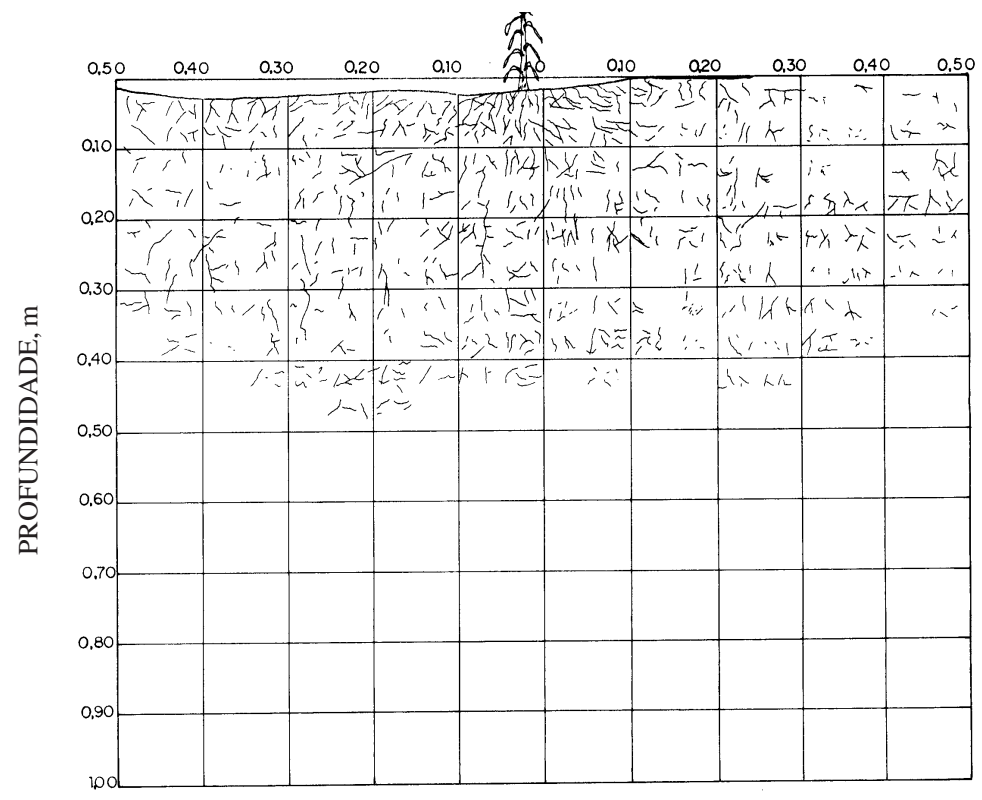

DISTÂNCIA DA PLANTA, $m$

Figura 1. Distribuição radicular da cultura do milho no perfil cultural com horizonte $A$ raso. Espessura dos horizontes: Ap1: 0-0,18 m; A2: 0,18-0,30 m; E : 0,30-0,45 m; $B_{\mathrm{t}}:$ 0,45-0,70 m; C: 0,70 m. 


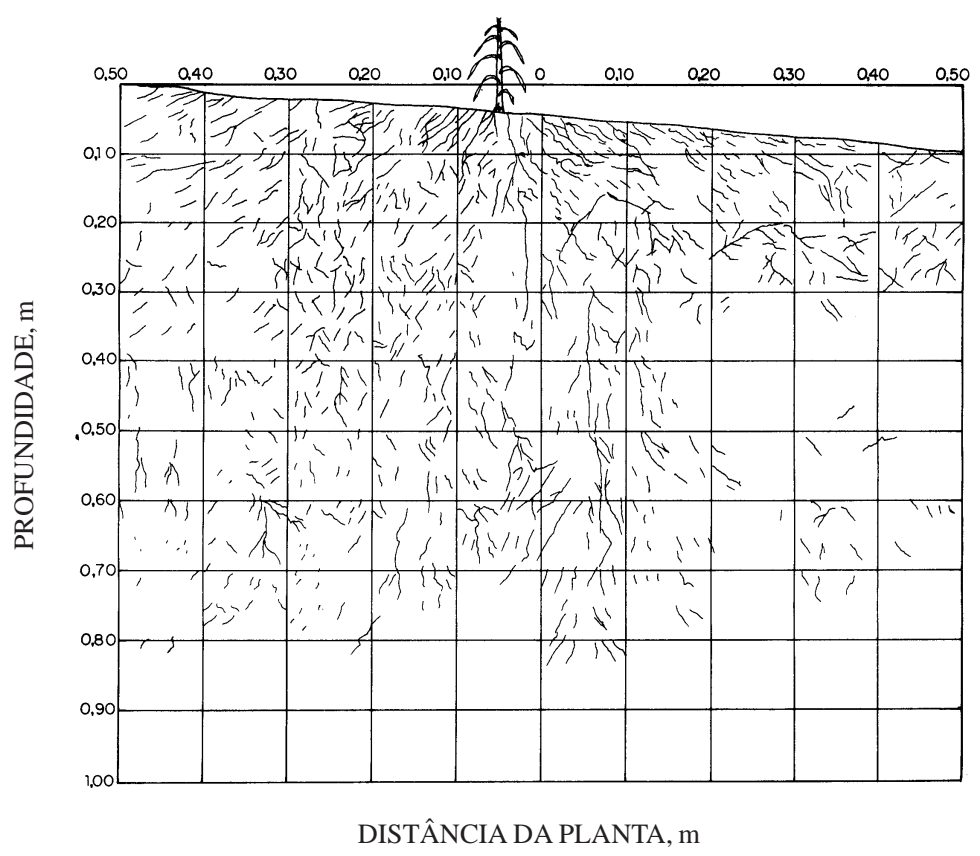

Figura 2. Distribuição radicular da cultura do milho no perfil cultural com horizonte $A$ profundo. Espessura dos horizontes: Ap1: 0-0,18 m; A2: 0,18-0,45 m; E : 0,45-0,70 m; BE : 0,70-0,83 m; B: 0,83 m+.

Observou-se, visualmente, que as plantas de milho apresentavam enrolamento de fol has apenas na área com horizonte A "raso". O sintoma de estresse hídrico foi observado, pois ocorreu um período prol ongado sem precipitação, que iniciou no final de dezembro ese estendeu atéo final dejaneiro, reduzindo, sensivelmente, a umidade do solo nas camadas superficiais, para valores próximos a $0,13 \mathrm{~cm}^{3} \mathrm{~cm}^{-3}$, nos perfis rasos, e $0,16 \mathrm{~cm}^{3} \mathrm{~cm}^{-3}$, nos profundos (Figuras 3 e 4). Dado o período de estiagem, as maiores umidades foram observadas nas camadas mais profundas de ambos os perfis avaliados, com val ores próximos a $0,33 \mathrm{~cm}^{3} \mathrm{~cm}^{-3}$, nos perfis rasos e $0,36 \mathrm{~cm}^{3} \mathrm{~cm}^{-3}$, nos perfis profundos (Figuras 3 e 4). A umidade nas camadas mais profundas não variou ao longo do período monitorado, possivel mente, pela ausência de raízes e baixa ascensão de água por capilaridade. Constatou-se que a restrição ao crescimento deraízes no horizonte $B_{t}$ não foi devida à falta de umidade, já que, nas camadas mais profundas, a umidade foi maior do que nas camadas mais rasas.

As mai ores flutuações da umi dade do sol o foram verificadas nos perfis com horizonte $A$ raso (Figura 3), o que provavel mente está rel acionado não só com a maior extração de água pelas plantas de milho na camada superficial de solo em períodos de déficit hídrico, mas também com a menor redistribuição da água para camadas mais profundas em períodos de maior precipitação, considerando a menor condutividade hidráulica do horizonte B textural.
Em todo o período monitorado, nos perfis com horizonte $\mathrm{A}$ raso e profundo, o espaço aéreo na profundidade de $0,45 \mathrm{~m}$ foi superior ao valor considerado crítico ao crescimento de raízes, de $0,10 \mathrm{~cm}^{3} \mathrm{~cm}^{-3}$ (Figuras 3 e 4). Durante os meses de outubro e novembro, período de maior taxa de crescimento da cultura, a umidade no horizonte $\mathrm{B}$ textural dos perfis rasos foi alta, resultando num espaço aéreo próximo a $0,13 \mathrm{~cm}^{3} \mathrm{~cm}^{-3}$ (Figura 3). Este baixo espaçoaéreo podeser oresponsável pela redução no crescimento de raízes, pois, com a profundidade, a taxa de difusão de oxigênio diminui mesmoem sol os com el evada macroporosidade(Hillel, 1980). Segundo Glinski \& Lipiec (1990), raízes de plantas que não toleram déficit de oxigênio evitam crescer em zonas com quantidades baixas deste el emento.

O maior volume de microporos com a profundidade deveu-se ao maior teor de argila no horizonte B textural (Quadro 1 eF igura 5). No perfil raso 1 , a microporosidade variou de 0,28 , no horizonte $A$, para $0,44 \mathrm{~cm}^{3} \mathrm{~cm}^{-3}$, no $B$ textural, enquanto a quantidade de macroporos neste horizonte foi menor do que $0,10 \mathrm{~cm}^{3} \mathrm{~cm}^{-3}$.

O diâmetro médio das raízes principais e laterais de primeira ordem de milho, segundo Glinski \& Li piec (1990), mede, respectivamente, 1.037 e $314 \mu \mathrm{m}$ em perfis com baixa densidade do solo e 2.208 e $640 \mu \mathrm{m}$ em sol o severamente compactado. Portanto, as raízes principais e laterais de primeira ordem dificilmente crescem em microporos ( $<48 \mu \mathrm{m})$ predominantes no horizonte $B_{t}$ dos perfis avaliados (Quadro 1). Segundo Glinski \& Lipiec (1990), em 


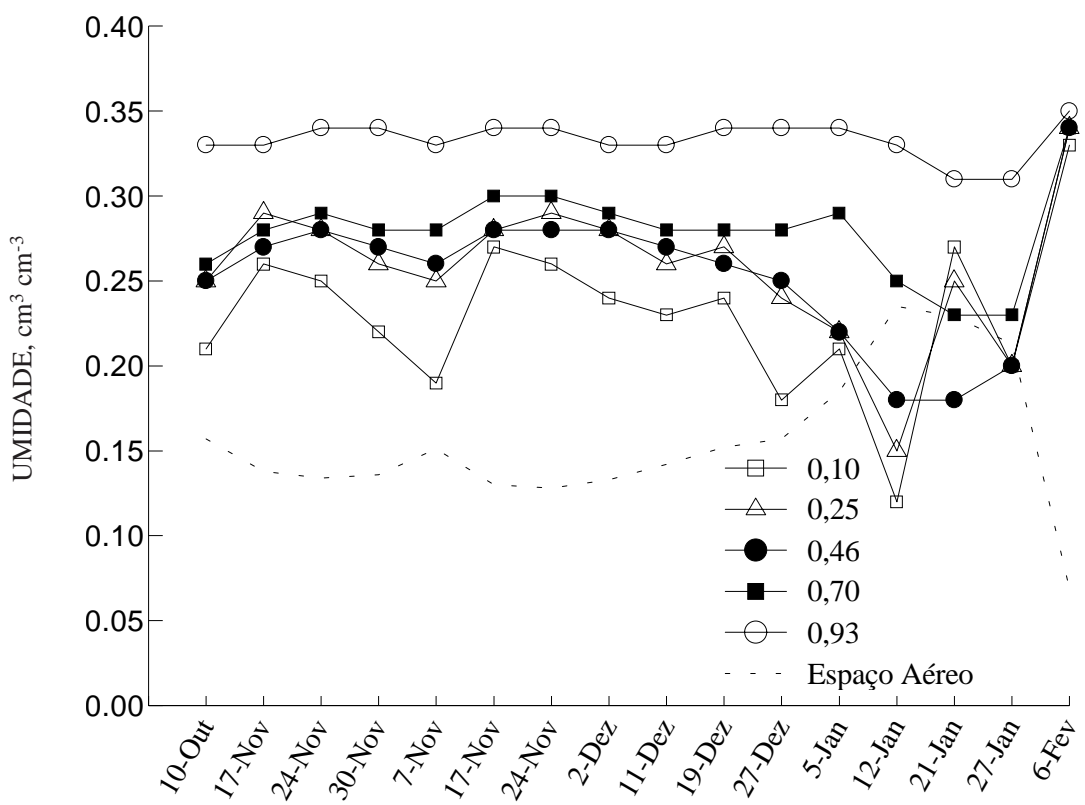

Figura 3. Variação temporal da umidade do solo determinada a $0,10,0,25,0,46,0,70$ e $0,93 \mathrm{~m}$ de profundidade e espaço aéreo na camada de $0,45 \mathrm{~m}$. Cada ponto é a média das leituras dos dois perfis com horizonte A raso.

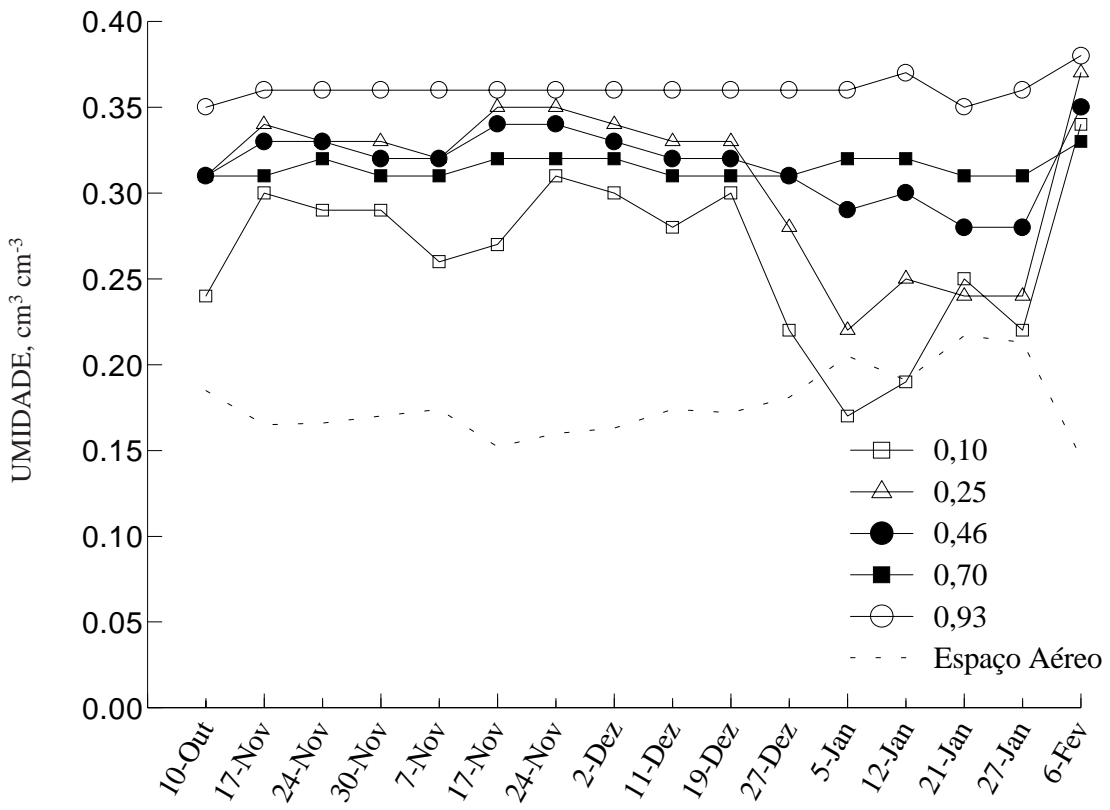

Figura 4. Variação temporal da umidade do solo determi nada a $0,10,0,25,0,46,0,70$ e $0,93 \mathrm{~m}$ de profundidade e espaço aéreo na camada de $0,45 \mathrm{~m}$. Cada ponto é a média das leituras dos dois perfis com horizonte A profundo.

sistemas rígidos, ou seja, sem expansão, raízes de milho não crescem em poros com diâmetro menor que 138 um de diâmetro; todavia, em sistemas nãorígidos, que apresentam expansão, podem crescer em poros de $46 \mu \mathrm{m}$ de diâmetro. Assim, se considerar que no subsolo o ambiente está mais rígido, o crescimento de raízes em microporos é dificultado.
É importanteressaltar que, dependendo do diâmetro médio das raízes principais e laterais de primeira ordem de milho, pode haver restrição ao crescimento radicular no horizonte $B_{t}$ nos perfis com horizonte $A$ "raso". I sso se deve à interação de fatores como a presença de concreções, el evado teor de argila e baixa quantidade de macroporos e espaço aéreo. 


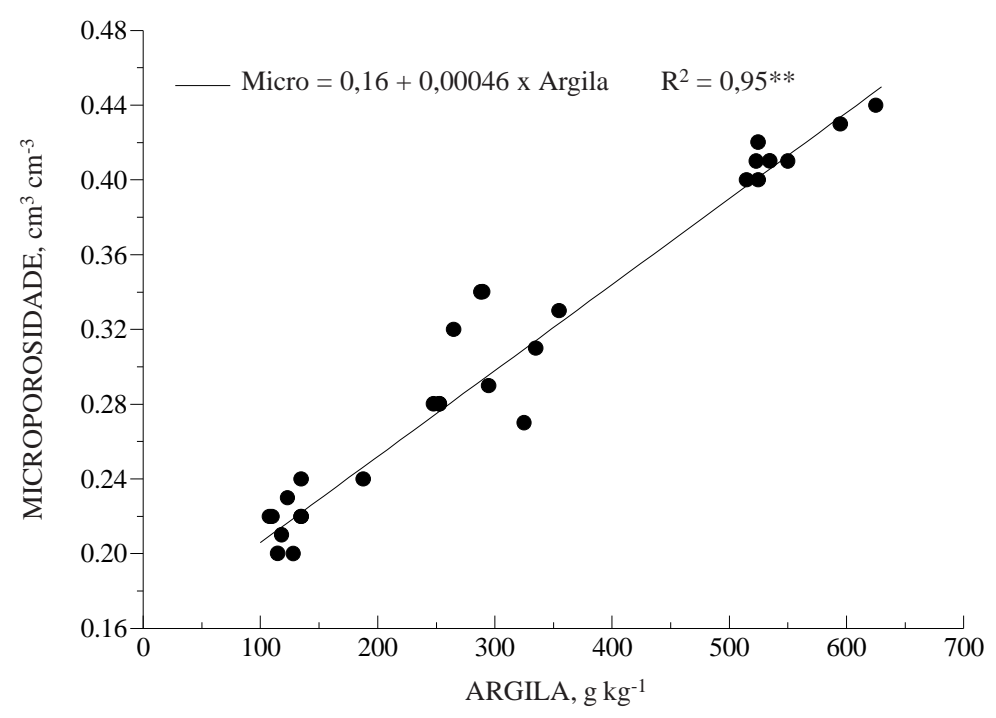

Figura 5. Relação entre a microporosidade e os teores de argila do solo dos perfis profundos e rasos no Argissolo Vermel ho distrófico arênico. $n=28$ pares, $* *$ significativo a $1 \%$ pelo teste $t$.

Outro fator que pode restringir o crescimento das raízes é a presença de camadas compactadas. Os valores de densidade do solo variaram de 1,29 a $1,71 \mathrm{~g} \mathrm{~cm}^{-3}$ (Quadro 1). N os perfis com horizonte A raso, as mai ores densidades dosol oforam observadas no horizonte $A$, enquanto, nos perfis com horizonte $A$ profundo, a densidade do solo foi alta em todas as camadas analisadas. Observou-sequea densi dade do solonãorestringiu ocrescimento radicular, pois mesmo onde foi observada densidade do solo el evada, a densidade radicular foi alta, como ocorreu na primeira camada do perfil profundo 1 (Quadros 1e2).

O aumento da densi dade do sol ogeral menteel eva a resistência à penetração. A resistência do solo à penetração foi superior a $2,6 \mathrm{~kg} \mathrm{~cm}^{-2}$ e na superfície chegou ao limite máximo do penetrômetro de bolso utilizado, $5 \mathrm{~kg} \mathrm{~cm}^{-2}$ (Quadro 1), valores que podem causar restrição ao crescimento de raízes. Deve-se considerar, porém, que, no momento da determinação da resistência à penetração, a superfície do solo estava com pouca umidade (Figuras 3 e 4).

No trabalho realizado por Taylor \& Gardner (1963) para a densidade do sol o de $1,7 \mathrm{~g} \mathrm{~cm}^{-3}$ em dois potenciais de água no solo, $-0,020$ e -0,067 MPa, a resistência do solo foi, respectivamente, de 0,8 e 3,0 MPa. Estes autores observaram que o aumento na resistência do sol o reduziu a penetração de raízes de algodão para valores próximos a zero. Veen \& Boone (1990) relataram que as raízes de milho cessaram o crescimento quando a resistência à penetração al cançou 4,7 MPa ou quando o potencial matricial de água foi inferior a -1,7 MPa. Em Latossolo Argiloso, Cintra \& Mielniczuk (1983) e Alvarenga et al. (1996) observaram restrição ao crescimento das raízes quando a resistência à penetração foi de 1,08 e 1,47 MPa, respectivamente.
J á Rosolem et al. (1994), em Latossolo arenoso, observaram tal efeito para val ores próximos a 2,0 M Pa.

Segundo Bowen et al. (1994), raízes de várias culturas desenvolvem pressões na direção axial de 0,9 a 1,5 MPa. O milho desenvolve pressões de 1,22 MPa na direção axial e de 0,67 a 0,71 MPa na direção radial. N esses estudos, as relações entre a umidade, densidade do solo, textura e resistência à penetração mostraram-se complexas. Vale destacar que a comparação dos resultados da literatura com os encontrados nesteestudo não é possível por serem o equipamento e as unidades utilizadas para expressar a resistência à penetração diferentes.

A presença de concreções reduziu o crescimento radicular (Figura 6), pois, nas amostras com mais de $100 \mathrm{~g}$ de concreções $\mathrm{kg}^{-1}$ de solo, a densidaderadicular foi menor que $1 \mathrm{~cm} \mathrm{~cm}^{-3}$, e, nas amostras com menos de $100 \mathrm{~g} \mathrm{~kg}^{-1}$, a densidade radicular foi variável. As concreções obstruem o crescimento radicular e desviam sua trajetória de crescimento (Pagès $\&$ Pellerin, 1994). Em horizontes ou camadas com concreções, o volume de sol o explorado pelas raízes e, conseqüentemente, a disponibilidade de água e nutrientes são reduzidos. Nas amostras avaliadas, várias apresentaram mais de $100 \mathrm{~g} \mathrm{~kg}^{-1}$ de concreções.

A saturação por alumínio foi maior que $50 \%$ no horizonte $\mathrm{B}_{\mathrm{t}}$, principalmente nos perfis com horizonteA raso, com val ores de 55 a 71\% (Quadro 1) e apresentou relação negativa com a densidade radicular (Quadro 2). Os teores de cálcio mais magnésio variaram de 1,9 a $4,0 \mathrm{cmol} \mathrm{kg}^{-1}$ e não apresentaram relação com a densidaderadicular. $\mathrm{Na}$ análise dos coeficientes de correlação, observou-se que nenhuma propriedade isolada foi responsável pela restrição ao crescimento das raízes no horizonte $\mathrm{B}$ textural. 
Quadro 2. Coeficiente linear (a) e angular (b) da equação da reta ajustada, coeficientes de determi nação $\left(R^{2}\right)$ e o nível de significância $(p)$, sendo $(X)$ as propriedades do Argissolo Vermelho distrófico arênico e (Y) a densidade radicular. Foram utilizados 28 pares de dados

\begin{tabular}{|c|c|c|c|c|c|c|c|c|c|c|}
\hline Coeficiente & $\mathrm{Ca}+\mathrm{Mg}$ & $m^{(1)}$ & $\operatorname{Mic}(2)$ & $\operatorname{Mac}^{(3)}$ & $\mathbf{P T} \mathbf{T}^{(4)}$ & $\mathbf{D s}^{(5)}$ & Argila & Silte & Areia & $\mathbf{R} \mathbf{P}^{(6)}$ \\
\hline a & (7) & 1,38 & (7) & (7) & 0,04 & 0,13 & 1,30 & 3,69 & 0,14 & $-1,34$ \\
\hline b & & $-0,01$ & & & $-3,40$ & 4,27 & 0,001 & $-0,01$ & 0,001 & 0,58 \\
\hline $\mathrm{R}^{2}$ & & 0,17 & & & 0,26 & 0,20 & 0,16 & 0,15 & 0,18 & 0,59 \\
\hline $\mathrm{p}$ & & 0,02 & & & 0,01 & 0,02 & 0,04 & 0,04 & 0,02 & 0,001 \\
\hline
\end{tabular}

(1) Saturação por alumínio. ${ }^{(2)}$ Microporosidade. ${ }^{(3)}$ Macroporosidade. ${ }^{\text {(4) }}$ Porosidade total. ${ }^{\text {(5) }}$ Densidade do solo (Ds). ${ }^{\text {(6) }}$ Resistência à penetração. ${ }^{(7)}$ Não-significativo $(p=0,05)$.

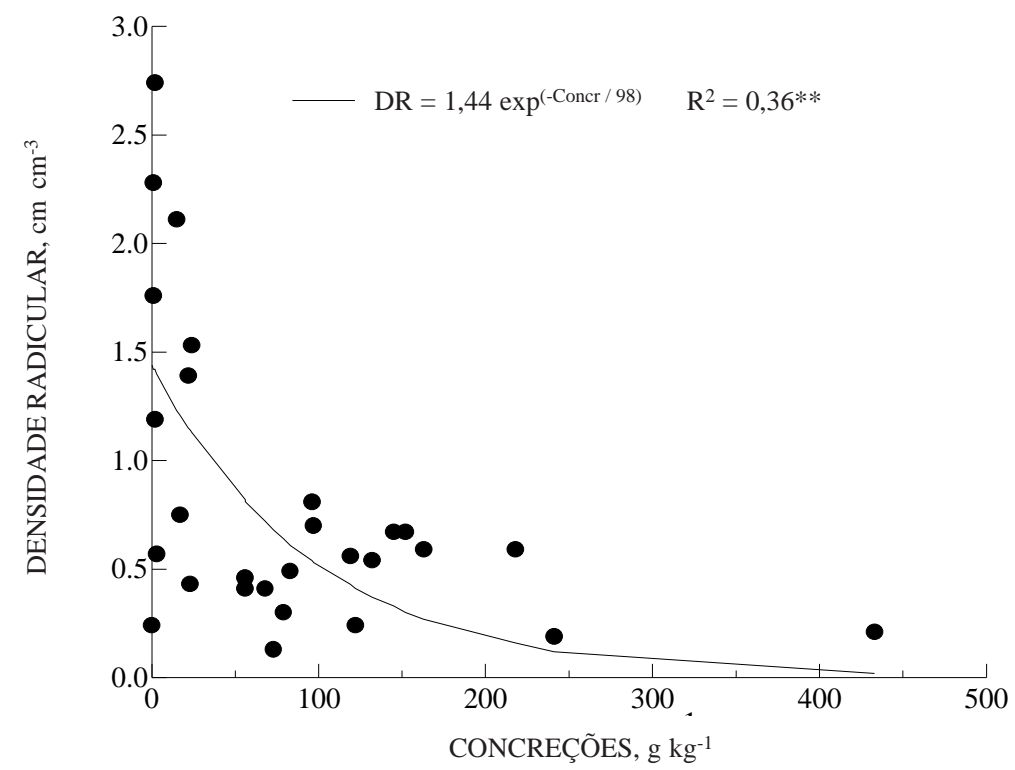

Figura 6. Relação entre a densidade radicular e os teores de concreções no solo, dos perfis profundos e rasos no Argissolo Vermelho distrófico arênico. $n=28$ pares, $* *$ significativo a $1 \%$ pelo teste $t$.

A análise por regressão múltipla indicou que a densidade radicular (DR) foi maior quando a quantidade de concreções (concr) foi menor e a densidade dosolo(Ds) maior (DR $=-2,1-0,003 *$ Concr $\left.+2,15^{*} \mathrm{Ds} ; \mathrm{R}^{2}=0,37 ; p=0,003\right)$. A relação positiva entre densidade radicular e densidade do solo foi observada, pois ambos foram al tos na superfície onde as raízes se concentraram e diminuíram em profundidade, principalmente nos perfis com horizonte A "raso".

O maior crescimento de raízes em profundidade resultou em aumento da produtividade do mil ho nos perfis com horizonte A "profundo". Na área onde estão local izados os perfis com horizonte A "raso", a produtividade de grãos foi de $3.916 \mathrm{~kg} \mathrm{ha}^{-1} \mathrm{e}$, nas áreas com horizonte A "profundo", foi de $5.085 \mathrm{~kg} \mathrm{ha}^{-1}$, diferença de $1.169 \mathrm{~kg} \mathrm{ha}^{-1}$ (23\% menor). Considerando a profundidade média de crescimento de raízes de
0,45 m para o horizonte $A$ raso, e de $0,80 \mathrm{~m}$, para o horizonte A profundo (Figuras 1 e 2), para cada centímetro de solo a menos explorado pelas raízes, a produtividade do milho foi reduzida em $35 \mathrm{~kg} \mathrm{ha}^{-1}$.

Na mesma área, Albuquerque et al. (1996) observaram, no ano agrícola de 1991/92, que, para cada centímetro a menos de horizonte A, a produtividade do milho foi reduzida em $43 \mathrm{~kg} \mathrm{ha}^{-1}$. Langdale et al. (1979), em uma pequena bacia hidrográfica com os sol os Hapludult e Dystrochrept, observaram que a produtividade do milho foi de $5.300 \mathrm{~kg} \mathrm{ha}^{-1}$, quando a espessura do horizonte $A$ era de $0,40 \mathrm{~m}$, e de $3.100 \mathrm{~kg} \mathrm{ha}^{-1}$, quando a espessura era de $0,25 \mathrm{~m}$, uma redução de $147 \mathrm{~kg} \mathrm{ha}^{-1}$ para cada centímetro a menos de horizonte A. M okma \& Sietz (1992) observaram em um Hapludalf, em um período de cinco anos, que a produtividade do milho em solo severamenteerodido foi $21 \%$ inferior à produtividade 
obtida para solo ligeiramente erodido. Nos dois últimos estudos, a produtividade foi menor em anos que ocorreram déficit hídrico.

Esta diferença está relacionada com o maior volume de solo explorado pelas raízes na área com horizonte A profundo, pois, segundo Eghball \& Maranville (1993), a restrição ao crescimento radicular diminui o acesso à água e nutrientes e, conseqüentemente, a produtividade. Segundo Swan et al. (1987), Mokma \& Sietz (1992) e Fiorin et al. (1997), a redução do crescimento radicular e, conseqüentemente, da produtividade do milhoé mais acentuada em anos de déficit hídrico.

\section{CONCLUSÕES}

1. O crescimento radicular da cultura do milho no horizonte $B$ textural foi restringido pela pequena quantidade de macroporos, presença de concreções e elevada saturação por alumínio, porém a el evada densidade do solo e resistência à penetração não afetaram o sistema radicular do milho.

2. A umidade do solo no horizonte $B$ textural não variou durante o período monitorado, decorrente da pequena presença de raízes edo reduzi do fenômeno da capilaridade ocorrido do horizonte B para o A.

3. A restrição ao crescimento radicular reduziu a produtividade de grãos de milho em $1.169 \mathrm{~kg} \mathrm{ha}^{-1}$ nos perfis com horizonte A raso, $35 \mathrm{~kg} \mathrm{ha}^{-1}$ para cada centímetro a menos de espessura de horizonte $\mathrm{A}$ explorado pelas raízes.

\section{AGRADECIMENTOS}

Os autores agradecem a Alberto Inda J únior e Flávio Fontinelli, pel o auxílio na col eta das amostras e determinações físicas.

\section{LITERATURA CITADA}

ALBUQUERQUE, J.A.; FIORIN, J.E. \& REINERT, D.J . Variabilidade espacial de propriedades do solo e produção de milho. In: CONGRESSO BRASILEIRO DE ENGENHARIA AGRÍCOLA，21; SIMPÓSIO DE ENGENHARIA AGRÍCOLA DO CONE SUL, 1., Santa Maria, 1992. Anais. Santa Maria, Sociedade Brasileira de Engenharia Agrícola, 1992. p.417-430.

ALBUQUERQUE, J.A.; REINERT, D.J .; DEBARBA, L. \& AMADO, T.J.C. Variabilidade espacial em parcelas experimentais de perda de água e solo por chuva natural . Ci. Rural, 24:269-273, 1994.

ALBUQUERQUE, J.A.; REINERT, D.J. \& FIORIN, J.E. Variabilidade de sol o e planta em solo Podzólico Vermel hoAmarelo. R. Bras. Ci. Solo, 20.151-157, 1996.
ALVARENGA, R.C.; COSTA, L.M.; MOURA FILHO, W. \& REGAZZI , A.J . Crescimento de raízes de leguminosas em camadas de solo compactadas artificialmente. R. Bras. Ci. Solo, 20.319-326, 1996.

BOWEN, H.D.; GARNER, T.H. \& VAUGHN, D.H. Advances in soil-plant dynamics. In: De VORE-HANSEN, P., ed. Advances in soil dynamics. St. J oseph, American Society of Agricultural Engineers, 1994. p.255-280.

BRASIL. Ministério da agricultura. Departamento Nacional de Pesquisa Agropecuária. Divisão de Pesquisa Pedológica. Levantamento de reconhecimento de solos do Estado do Rio Grande do Sul. Recife: 1973. 431p. (Boletim Técnico, 30)

CINTRA, F.L.D. \& MIELNICZUK, J. Potencial de algumas espécies vegetais para a recuperação de solos com propriedades físicas degradadas. R. Bras. Ci. Solo, 7:197201, 1983.

EGHBALL, B. \& MARANVILLE, J.W. Root development and nitrogen influx of corn genotypes grown under combined drought and nitrogen stresses. Agron. J., 85:147-152, 1993.

EMPRESA BRASILEIRA DE PESQUISA AGROPECUÁRIA EMBRAPA. Serviço Nacional de Levantamento e Conservação do Solo. Manual de métodos de análise de solo. 2ed. Rio de J aneiro, 1979. não paginado.

EMPRESA BRASILEIRA DE PESQUISA AGROPECUÁRIA EMBRAPA. Centro Nacional de Pesquisa de Solos. Sistema brasileiro de classificação de solos. Brasília, Embrapa produção de informações; Rio de J aneiro, 1999. 412p.

FIORIN, J.E. Armazenamento de água no solo, crescimento e produção do milho e teste de modelo de simulação. Santa Maria, Universidade Federal de Santa Maria, 1993. 128p. (Tese de Mestrado)

FIORIN, J.E.; REINERT, D.J . \& ALBUQUERQUE, J.A. Armazenamento deágua no solo e produtividade da cultura do milho em solo Podzólico Vermel ho-Amarelo. R. Bras. Ci. Solo, 21:249-255, 1997.

GERARD, C.J ., SEXTON, P. \& SHAW, G. Physical factors influencing soil strength and root growth. Agron. J ., 74:875879, 1982.

GLINSKI,J . \& LIPIEC, J . Soil physical conditions and plant roots. Boca Raton, CRC Press, 1990. 250p.

HILL, R.L. \& CRUSE, R.M. Tillage effects on bulk density and soil strength of two Mollisols. Soil Sci. Soc. Am. J ., 49:12701273, 1985.

HILLEL, D. Fundamentals of soil physics. London, Academic press, 1980. 413p.

LANGDALE, G.W.; BOX, J.E. \& LEONARD, R.A. Corn yield reduction on eroded southern piedmont soils. J. Soil Water Cons., 34:226-228, 1979.

LOGSDON, S.D.; RENEAU, R.B. \& PARKER, J .C. Corn seedling root growth as influenced by soil physical properties. Agron. J., 79:221-224, 1987.

MELLO IVO, W.M.P. \& MIELNICZUK, J . Influência da estrutura do solo na distribuição e na morfol ogia do sistema radicular do milho sob três métodos de preparo. R. Bras. Ci. Solo, 23:135-143, 1999. 
MENGEL, D.B. \& BARBER, S.A. Development and distribution of the corn root under field conditions. Agron. J., 66:341344, 1974.

MOKMA, D.L. \& SIETZ, M.A. Effects of soil erosion on corn yield on Marlet Soils in south central Michigan. J. Soil Water Cons., 47:325-327, 1992.

MORENO, J.A. Clima do Rio Grande do Sul. Porto Alegre, Secretaria da Agricultura, Diretoria de Terras e Colonização, Seção de Geografia, 1961. 46p.

NIZEYIMANA, E. \& OLSON, K.R. Chemical, mineralogical and physical property differences between moderately and severely eroded IIlinois Soils. Soil Sci. Soc. Am. J ., 52:17401748,1988

OUSSIBLE, M.; CROOKSTON, R.K. \& LARSON, W.E. Subsurface compaction reduces the root and shoot growth and grain yield of wheat. Agron. J., 84:34-38, 1992.

PAGÈS, L. \& PELLERIN, S. Evaluation of parameters describing the root system architecture of field grow maize plants (Zea mays, L.) II- Density, length, and branching of first-order lateral roots. Plant Soil, 164:169-176, 1994.

ROSOLEM, C.A.;VALE, L.S.R.; GRASSI FILHO,H.\& MORAES, M.H. Sistema radicular e nutrição do milho em função da calagem e da compactação do solo. Bragantia, 53:259-266, 1994.
SAS Institute. SAS/STAT Procedures guide for personal computers. Version 6. Cary, NC, 1990. 705p.

SILVA, V.R.; REINERT, D.J . \& REICHERT, J.M. Densidade do solo, atributos químicos e sistema radicular do milho afetados pelo pastejo e manejo do solo. R. Bras. Ci. Solo, 24:191-199, 2000.

SWAN, J.B.; SHAFER, M.J . \& PAULSON, W.H. Simulating the effect of soil depth and climatic factors on corn yield. Soil Sci. Soc. Am. J ., 51:1025-1032, 1987.

TAYLOR, H.M. \& GARDNER, H.R. Penetration of cotton seedling taproots as influenced by bulk density, moisture content, and strength of soil. Soil Sci., 96:153-156, 1963.

TENNANT, D. A test of a modified line intersect method of estimating root length. J. Ecol., 63:995-1001, 1975.

VEEN, B.W. \& BOONE, F.R. The influence of mechanical resistance and soil water on the growth of seminal roots of maize. Soil Till. Res., 16:219-226, 1990.

VYN, T.J . \& RAI MBAULT, B.A. Long-term effect of five systems on corn response and soil structure. Agron.J ., 85:1074-1079, 1993.

WILLIAMS, J .R.; ALLMARAS, R.R.; RENARD, K.G.; LYLES, L.; MOLDENHAUER, W.C.; LANGSDALE, G.W.; MEYER, L.P. \& RAWLS, W.J . Soil erosion effects on soil productivity: A research perspective. J. Soil Water Cons., 36:82-90, 1981. 
